\title{
Pyrimidoquinxoalinophenanthroline opens next chapter in design of bridging ligands for artificial photosynthesis
}

\author{
Jannik Brückmann, ${ }^{[a]}$ Carolin Müller, ${ }^{[b, c]}$ Tamar Maisuradze, ${ }^{[b]}$ Alexander K. Mengele, ${ }^{[a]}$ \\ Djawed Nauroozi, ${ }^{[a]}$ Sven Fauth, ${ }^{\left[{ }^{[a]}\right.}$ Andreas Gruber, ${ }^{[d]}$ Stefanie Gräfe, ${ }^{[b]}$ Kerstin Leopold, ${ }^{[d]}$ \\ Stephan Kupfer, ${ }^{[b]}$ Benjamin Dietzek-Ivanšić, ${ }^{*,[b, c]}$ Sven Rau*,[a]
}

[a] J. Brückmann, A. K. Mengele, S. Fauth, Dr. D. Nauroozi, Prof. Dr. S. Rau, Institute of Inorganic Chemistry I, Ulm University, Albert-Einstein-Allee 11, 89081 Ulm, Germany, E-mail: sven.rau@uni-ulm.de

[b] T. Maisuradze, Dr. C. Müller, Dr. S. Kupfer, Prof. Dr. S. Gräfe, Prof. Dr. B. DietzekIvanšić, Institute of Physical Chemistry ,Friedrich-Schiller University Jena, Helmholtzweg 4, 07743 Jena, Germany

[c] Dr. C. Müller, Prof. Dr. B. Dietzek-Ivanšić, Leibniz Institute of Photonic Technology (IPHT) e.V., Department Functional Interfaces, Albert-Einstein-Straße 9, 07745 Jena, Germany, E-mail: benjamin.dietzek@leibniz-ipht.de

[d] A. Gruber, Prof. Dr. K. Leopold, Institute of Analytical and Bioanalytical Chemistry, Ulm University, Albert-Einstein-Allee 11, 89081 Ulm, Germany

\begin{abstract}
Using a dehydrogenative chemistry on the complex approach, a new polypyridine bridging ligand that bridges the gap of already existing systems is synthesized. By the usage of versatile cross-coupling reactions two different coordination spheres are included in the ligand architecture. Due to the twisted geometry of the novel ditopic ligand, the resultant division of the ligand in two distinct subunits leads to steady state as well as excited state properties of the corresponding mononuclear $\mathrm{Ru}(\mathrm{II})$ polypyridine complex resembling those of prototype $\left[\mathrm{Ru}(\mathrm{bpy})_{3}\right]^{2+}$ (bpy $=2,2^{\prime}$-bipyridine). The localization of the initially optically excited and the nature of the long-lived excited states on the Ru-facing ligand spheres is evaluated by resonance Raman and fs-TA spectroscopy, respectively, and supported by DFT and TDDFT calculations. Coordination of a second metal ( $\mathrm{Zn}$ or $\mathrm{Rh})$ to the available bis-pyrimidyl-like coordination sphere strongly influences the frontier molecular orbitals apparent by e.g., luminescence quenching. Thus, the new bridging ligand motif offers electronic properties which can be adjusted by the nature of the second metal center. Using the heterodinuclear Ru-Rh complex, visible light-driven reduction of $\mathrm{NAD}^{+}$to $\mathrm{NADH}$ was achieved, highlighting the potential of this system for photocatalytic applications.
\end{abstract}

\section{Introduction}

Light-induced electron transfer lies at the heart of photosynthesis, the most important chemical transformation process on earth. ${ }^{[1]}$ Within artificial photosynthesis significant steps towards a deeper understanding of structural and electronic factors determining the efficiency of electron transfer rely on the interplay between advanced spectroscopic methods and the availability of suitable model systems. ${ }^{[2-6]}$ Heterooligonuclear metal complexes containing specific bridging ligands (BL) which determine the distance between the (photo)redox active metal centers, the degree of electronic coupling and the stability of the coordination centers utilizing the chelate 
effect have been pivotal for this development and yielded the discovery of supramolecular photocatalysts for water splitting. ${ }^{[7-10]}$ Access to fundamentally new bridging ligands is therefore a key requirement to improve our understanding of fundamental aspects of lightinduced electron transfer and at the same time enabling new applications in light-driven catalysis. Due to this, bridging systems of high rigidity with bipyridine- or phenanthroline-like coordination spheres providing sufficient stability were evaluated in numerous reports and review articles. ${ }^{[10-13]}$ Representative examples with increasing bridging ligand length would be the row of 2,2'-bipyrimidine (bpm), 1,6,7,12-tetraazaperylene (tape) or eilatin like structure and tetrapyrido[3,2-a:2',3'-c:3",2"-h:2'",3"'-j]phenazine (tpphz) (as depicted in Figure 1). Several mono- and dinuclear transition metal complexes of those relays have been investigated so far. ${ }^{[9,14-19]}$ Since $\left[R u(b p y)_{3}\right]^{2+}$-type complexes were extensively studied upon their chemical, photophysical and photochemical properties, fundamental studies on complexes with $\mathrm{Ru}(\mathrm{II})$ photosensitizing and bpym (2,2'-bipyrimidine), ${ }^{[18,20-22]}$ tape (tetraazaperylene or dipyrido[4,3,2de:2', 3',4'-gh][1,10]phenanthroline), ${ }^{[14,15,23,24]}$ eilatin ${ }^{[24,25]}$ and tpphz (tetrapyrido[3,2-a:2',3'c:3",2"-h:2'",3'"-j]phenazine) $)^{[9,17,26]}$ bridging unit were made. For bpym- and tape-like dinuclear complexes relatively strong ground-state coupling between both metal centers has been observed whereas tpphz seems to largely decouple them. ${ }^{[15,20]}$ Photocatalytic hydrogen formation with related Ru-BL-Pd catalysts is only observed with tpphz. ${ }^{[9]}$ However, tpphz utilization is hampered by a low lying phenazine-based accepting orbital severely limiting the choice of reducible catalytic metal centers. Principal access to a bridging ligand with shorter metal-to-metal distances and potentially sufficient degree of electronic decoupling can be derived starting from 5,6-disubstituted 1,10-phenanthroline.

Glazer and Tor presented synthetic concepts for dehydrogenative CC coupling chemistry in related systems, ${ }^{[24]}$ which should enable a route towards the target unit. First, coupling of 5substituted pyrimidine to a $\mathrm{Ru}(\mathrm{II})$ 1,10-phenanthroline system at its 5,6 positions via $\mathrm{Pd}$ catalysed cross-coupling reactions was performed. This was followed by the built-up of a conformationally rigid bridging ligand via $\mathrm{Pd}$ on charcoal activated ring-closure procedure reported earlier by Glazer and Tor. ${ }^{[24]}$

This contribution introduces the synthesis of a novel bridging ligand coordinated to a ruthenium center to bridge the gap between already existing systems. The synthesis is complemented by detailed structural and electronic characterization by optical spectroscopy and quantum chemistry. Furthermore, its ability for coordination of a second metal center i.e., with respect to future applications in the scope of photocatalysis, is explored.

\section{Results and Discussion}

The synthesis of $\mathrm{Ru}(\mathrm{II})$ polypyridine complexes bearing $\pi$-extended, $\mathrm{N}$-heterocycle substituted 1,10-phenanthroline (phen) type ligands was performed via two different transition metal catalysed cross-coupling reactions at the dibrominated Ruphen $\mathrm{Br}_{2}$-type (i.e. $\left[(\text { tbbpy })_{2} \mathrm{Ru}\left(\text { phenBr }_{2}\right)\right]^{2+} ;$ tbbpy $=4,4^{\prime}$-di-tert-butyl-2,2'-bipyridine; phenBr $_{2}=5,6$-dibromo-1,10phenanthroline) precursor and a thermal dehydrogenation reaction using palladium on charcoal $(\mathrm{Pd} / \mathrm{C})$.

Starting from the dibrominated, literature-known compound $\mathbf{R u p h e n} \mathbf{B r}_{2}$ either Suzuki or Stille reactions were used to form the 1,10-phenanthroline-5,6-bis-pyrimidine substituted complex Rudpymp ([(tbbpy) ${ }_{2} R u(\text { dpymp) }]^{2+} ;$ dpymp = 5,6-di(pyrimidin-5-yl)-1,10-phenanthroline). So far, literature examples upon cross-coupling approaches with 5,6-dibromo-1,10phenanthroline only used electron-rich organometallic derivatives like donor-substituted phenyl or thiophene moieties. ${ }^{[27]}$ Only few articles integrate acceptor-substituted phenyl compounds because monosubstitution and/or dehalogenation reactions hamper those synthetic pathways. ${ }^{[28]}$ Especially, cross-coupling with electron-deficient nitrogen heterocycles proves to be challenging. ${ }^{[29-31]}$ Published reaction conditions for Stille cross-coupling yielded 
exclusively in mono-substitution and concomitant dehalogenation of the second halogen substituent. ${ }^{[32-35]}$ Usage of copper iodide additive ${ }^{[36,37]}$ di-substitution leads to Rudpymp in a yield of up to $67 \%$. To our own surprise, Suzuki cross-coupling with standard reaction conditions ${ }^{[27]}$ gave excellent yields up to $88 \%$. Purification in both cases was done via slow diffusion of diethyl ether into a concentrated solution of Rudpymp in acetonitrile.
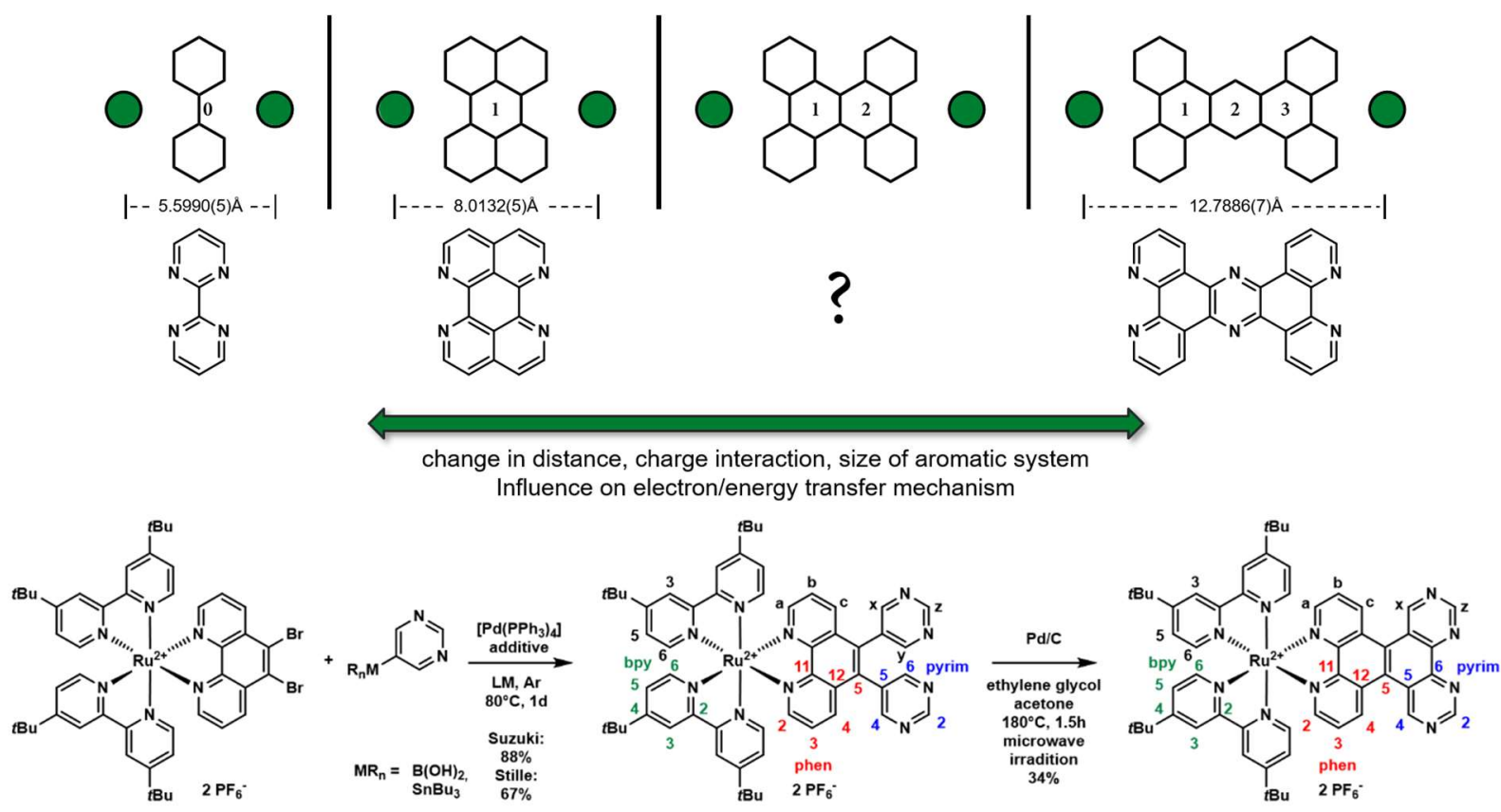

$\left[(\text { tbbpy })_{2} \mathrm{Ru}(\text { phenBr})\right]^{2+}$

$\left[\left(\text { tbbpy) }{ }_{2} \text { Ru(dpymp) }\right]^{2+}\right.$

$\left[(\text { tbbpy })_{2} R u(\text { pqp })\right]^{2+}$

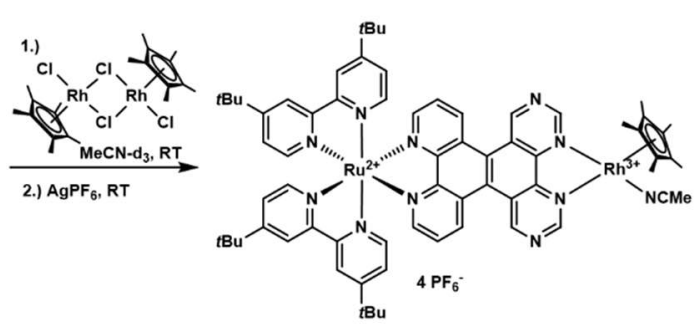

$\left[(\text { tbbpy })_{2} \mathrm{Ru}(\text { pqp)Rh(NCMe)(Cp*) }]^{4+}\right.$

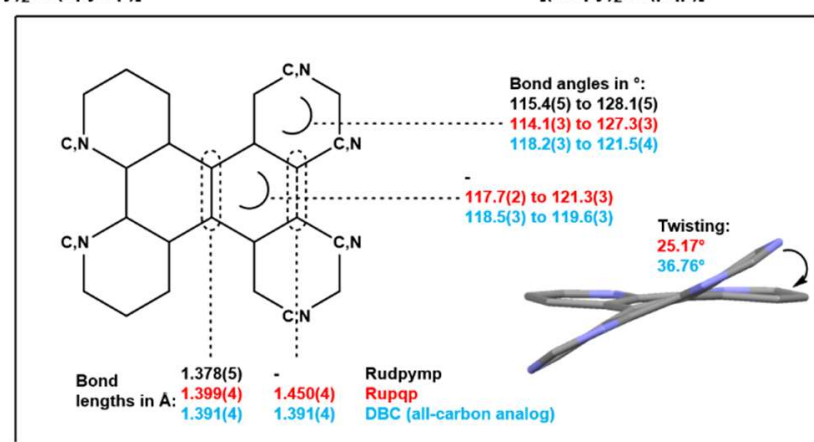

Figure 1. Top: Overview of the existent bridging ligand structures and selected metal-to-metal distances from solid state structures of $\left[(\mathrm{bpy}){ }_{2} \mathrm{Ru}(\mathrm{bpym}) \operatorname{Ir}\left(\mathrm{Cp}^{*}\right)\right]^{2+},{ }^{222]}[(\mathrm{L}) \mathrm{RutapeRu}(\mathrm{L})]^{4+}$ (with $\mathrm{L}=\mathrm{N}, \mathrm{N}^{\prime}$-dimethyl-2,11-diaza-[3.3](2,6)-pyridiophane $)^{[14]}$ and [(tbbpy ${ }_{2}$ RutpphzRu(tbbpy) $\left.{ }_{2}\right]^{4+}{ }^{49]}$ Bottom: Synthetic protocol for Suzuki and Stille cross coupling reactions and the following ring closing reaction; positions of the respective protons (in black) and carbon atoms (coloured; with ligand (sphere) abbreviations) were marked; inset shows a part of the all-carbon analog dibenzo[g,p]chrysene (DBC) or pqp framework and the discussed bond angles and lengths; additionally, a part of the solid-state structure of Rupqp is used to visualize the twisting compared to all-carbon DBC derivatives; colour code: Rudpymp (black), Rupqp (red), DBC (light blue).

To achieve a fully ring-closed system of the bis-pyrimidyl substituted phenanthroline moiety, dehydrogenation reactions were conducted. Literature-known cyclization with $\mathrm{Pd} / \mathrm{C}$ in ethylene glycol and acetone under elevated temperatures gave an NMR-detectable amount of Rupqp $\left(\left[(\text { tbbpy })_{2} R u(\text { pqp })\right]^{2+} ; \quad\right.$ pqp $=$ pyrimido[5',4':7,8]quinazolino[5,6-f][1,10]phenanthroline $)$. Improving the reaction conditions (additive(s), temperature, time; see chapter 3.4 in $\mathrm{SI}$ ) and running this reaction in a microwave setup significantly increased yields (from NMR-detectable to $34 \%$ yield). Strikingly, the reaction was not possible using Rudpymp obtained under Stille 
conditions. In total reflection X-ray fluorescence spectroscopy (TXRF) significant residues of copper and iodide could be detected (see Figure S66). To verify that one of these elements prohibits the ring closure reaction, copper iodide was added deliberately to the Suzuki product. As under these conditions the ring-closure reaction failed as well, the inhibiting effect of Cul residues on the cyclization reaction is demonstrated (see Figures S37 and S38).

After the ring closure, Rupqp offers a second coordination sphere. This chelating ligand sphere emerges as an electron deficient 4,4'-bipyrimidyl-like environment. To evaluate the ability to attach a second metal center to Rupqp, we decided for the typically efficiently introducible $\mathrm{Rh}\left(\mathrm{Cp}^{*}\right)(\mathrm{X})\left(\mathrm{Cp}{ }^{*}=\right.$ pentamethylcyclopentadienyl) fragment. Earlier reports accomplished the coordination by simply stirring both the bridging ligand containing Ru-complex and the Rh(III) dimer in solution of e.g. methanol or methylene chloride, the latter was applied for example for $\left[(\text { tbbpy })_{2} \mathrm{Ru}(\mathrm{tpphz})\right]^{2+}\left(\mathrm{i} . \mathrm{e} .\left[(\mathrm{tbbpy}){ }_{2} \mathrm{Ru}(\mathrm{tpphz})\right]^{2+}\right) \cdot{ }^{[38,39]}$ Within this work, this attempt yielded only partial conversion. Follow-up purification steps with solvents with (even partial) donor capability, ended in partial chlorido ligand substitution by solvent molecule(s). Due to this ligand lability, earlier described methods were used to cleave the chlorido ligand quantitatively by addition of silver hexafluorophosphate. ${ }^{[40]}$ To exclude insoluble silver chloride, several centrifugations in methylene chloride and subsequent re-crystallization were done. Possibly due to soluble silver clusters as it was shown earlier, ${ }^{[41]}$ atomic absorption spectrometry (AAS) still reveals silver contaminations (see ESI Figure S67).

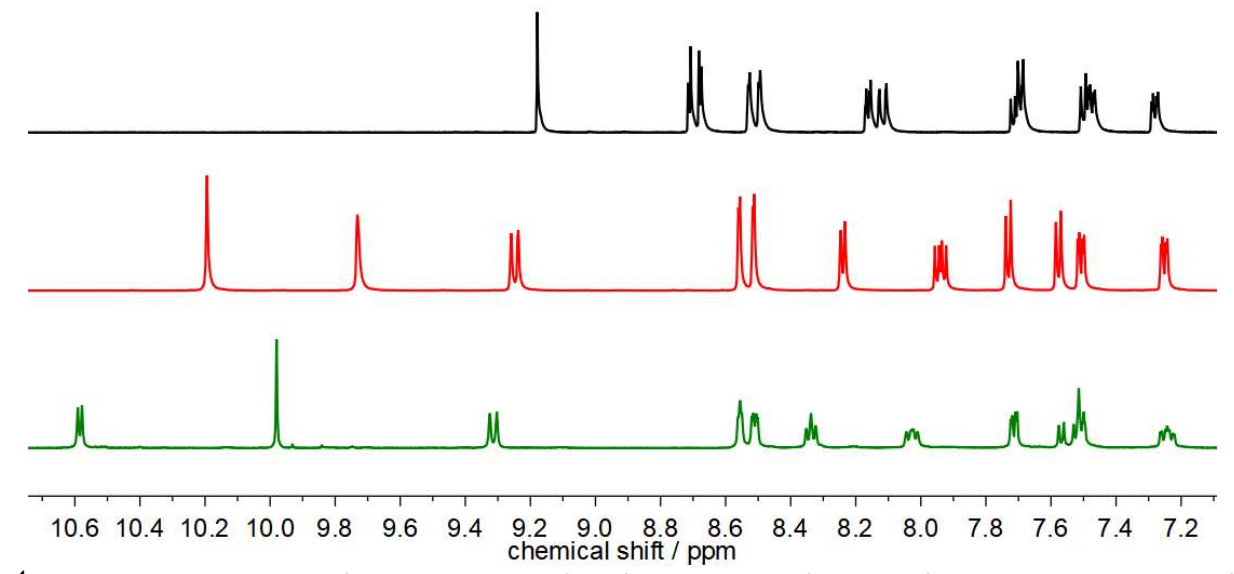

Figure 2. ${ }^{1} \mathrm{H}$ NMR spectra of Rudpymp (top), Rupqp (middle) and RupqpRh (bottom) in acetonitrile- $\mathrm{d}_{3}(400 \mathrm{MHz}$, due to absence of concentration dependence as shown in Figures S23 and S24 no specific concentrations were used).

For the ${ }^{1} \mathrm{H}$ NMR spectra of Rudpymp and Rupqp, the signal pattern is simplified upon ring closure from dpymp to pqp (see Figure 2). This is due to the long-range coupling of protons $x$ and $y$ which causes - in addition to proton $z-a$ second singlet to appear (see Figure 1 for the assignment). All pyrimidine protons and the c protons of the phen (1,10-phenanthroline) sphere are considerably shifting downfield due to the ring-closed system and even further due to coordination of $\mathrm{Rh}(\mathrm{III})$. To exclude effects of silver ions, $\mathrm{AgPF}_{6}$ was added to Rupqp which does not induce changes in the chemical shifts (see Figure S44). Upon ring closure, changes in the chemical shift of maximal $1.5 \mathrm{ppm}\left(\mathrm{H}_{\mathrm{x}}\right)$ can be observed. This effect diminishes progressively when moving from the inner ligand sphere to the adjacent phenanthroline/pyrimidyl positions and the peripheral tert-butyl-bipyridines. Two possible explanations for this effect might be i) a varied ring current leading to altered deshielding/shielding of the different moieties or their adjacent aromatic rings and/or ii) an enhanced conjugation between phenanthroline and bis-pyrimidyl spheres upon ring closure. ${ }^{[42,43]}$ The latter clearly can be seen in analysing bond lengths and torsion angles within the pqp ligand (vide infra). The electron poor character of the pqp ligand sphere is further enhanced by coordination of Rh(III). Again, changes of the chemical shifts are of significant 
level for the nearby pyrimidyl protons and diminishes for the farther apart phen and tbbpy protons.

Compared to complexes bearing shorter (e.g. $\left[(\text { bpy })_{2} \operatorname{Ru}(\text { tape })\right]^{2+[15]}$ ) and longer (e.g. Rutpphz $z^{[44]}$ ) bridging ligands, Rudpymp and Rupqp show no concentration dependence in acetonitrile within a concentration range of $1.3 \mathrm{mM}$ to 30.3 or $18.5 \mathrm{mM}$, respectively (see Figures S23 and S24). The mononuclear complex of tape shows rather small proton chemical shifts (up to $0.29 \mathrm{ppm}$ ) in a similar concentration range, but they appear to be too small to calculate a dimerization constant. In high contrast, the tpphz complex exhibits large shifts and consequently high dimerization constants $\left(120 \pm 19 \mathrm{M}^{-1}\right){ }^{[44]}$ This is surpassed by the eilatin (dibenzo[b,j]-dipyrido[4,3,2-de:2',3',4'-gh][1,10]phenanthroline; $\left.260 \mathrm{M}^{-1}\right)^{[25]}$ and dbneil (dibenzo[b,j]diquinolino[4,3,2-de:2',3',4'-gh][1,10]phenanthroline; $\left.750 \mathrm{M}^{-1}\right)^{[45]}$ complexes of $\left[(\text { bpy })_{2} R u(X)\right]^{2+}$ type structure.

\section{Single crystal analysis}

Suitable crystals for X-ray diffraction analysis were obtained by slow evaporation of appropriate solvent mixtures (for details see SI). The solid-state structures of Rudpymp and Rupqp shown in Figure 3 reveal typical bite angles of $78.19(9)^{\circ}$ to $79.6(1)^{\circ}$ for the tbbpy ligands and $78.5(1)^{\circ}$ (Rudpymp) or $78.33(9)^{\circ}$ (Rupqp) for the novel ligand moiety. Rudpymp exhibits torsion angles of the two pyrimidine units of $70.25^{\circ}$ and $62.77^{\circ}$ with respect to the phenanthroline plane. The range of the observed torsion angels is in accordance to other $\sigma \mathrm{v}$ symmetric systems reported in literature. ${ }^{[28]}$ Medium steric hinderance produced by the $\mathrm{x}$ protons (recall Figure 1) of the pyrimidine rings yields less tilted geometries than observed for higher sterically crowded substituents. ${ }^{[32]}$ Hydrogen bonding of one of the pyrimidine nitrogen atoms of Rudpymp towards co-crystallized water $(1.884 \AA)$ may affect this as well.
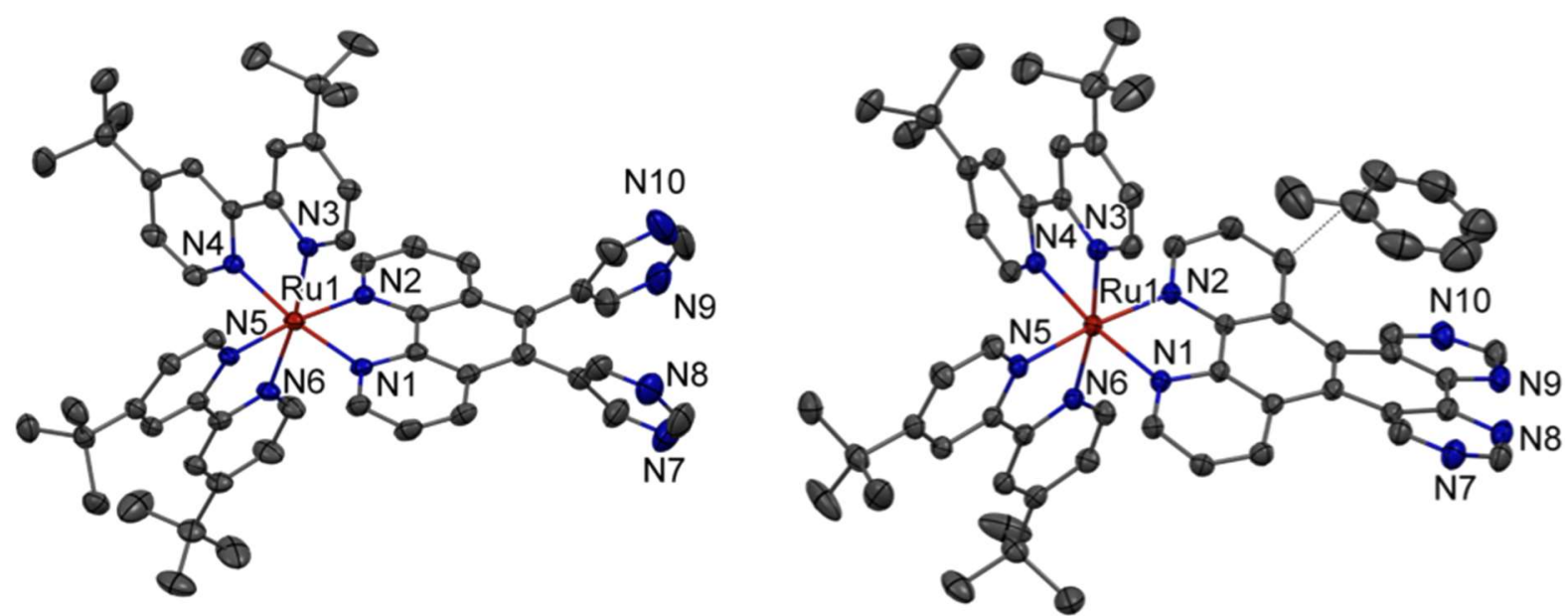

Figure 3. Solid-state structure of Rudpymp (left) and Rupqp (right) (thermal ellipsoids are drawn at a probability level of $50 \%$ ). Hydrogen atoms, $\mathrm{PF}_{6}^{-}$counter anions and solvent molecules are omitted for clarity; additionally, intermolecular interactions of a toluene molecule with Rupqp are depicted.

Upon ring closure, Rupqp reveals a conformationally rigid chemical structure where the pyrimidyl units in the backbone are attached to each other directly (see schematic representation in Figure 1). Rupqp exhibits shortening of the bonds between the phenanthroline (C5 and C6, see Figure 1) and pyrimidyl units (C5). Bond lengths decrease from 1.490(5) $\AA$ and 1.492(5) $\AA$ to 1.455(4) $\AA$ and 1.459(4) $\AA$, respectively. Additionally, interior angles of the pqp ligand deform upon ring closing (range from $114.07^{\circ}$ up to $127.34^{\circ}$ ), whereas 
the angles in the new, central sphere are more evenly distributed (from $117.69^{\circ}$ up to $121.28^{\circ}$ ). Similar to DBC $\left(1.388 \AA{ }^{[46]} 1.397 \AA^{[47]}\right)$, the bond between $\mathrm{C} 5$ and $\mathrm{C} 6$ of the phenanthroline moiety $(1.399(4) \AA)$ is in the range of typical benzene-like $s^{2}-s p^{2}$ hybridized, aromatic C-C bonds with bond lengths of about $1.40 \AA{ }^{[42,48]}$ In addition, both pqp and DBC reveal a slightly longer bond length (1.450(4) $\AA$ ) between the aromatic rings in the backbone (each C6 atom of the pyrimidyl units, see Table 1 ).

Table 1. Comparison of Rupqp with literature examples on all-carbon dibenzo[g,p]chrysene derivatives; TMS $=$ trimethylsilyl.

\begin{tabular}{lll}
\hline Compound & Bond length central ring $[\AA]$ & Torsion angles $\left[^{\circ}\right]$ \\
\hline Rupqp (DFT) & $1.399(4)(1.404)$ & $25.17(29.5)$ \\
Dibenzo[g,p]chrysene ${ }^{[49,50]}$ & $1.388(2) / 1.391(4)$ & 38.94 \\
Bis-Pd-dicarbocorrole ${ }^{[47]}$ & $1.450(4)$ & 29.95 \\
Tetra-TMS-DBC[51] & $1.387(3)$ & 44.95 \\
DBC-Cl2 $^{[52]}$ & $1.37(2)$ & 40.65 \\
\hline
\end{tabular}

Possibly due to steric strains between the hydrogens at the $x$ position of the pyrimidine and $c$ of the phenanthroline, a tilted geometry of the pqp can be found in the solid-state structure. A torsion angle of $25.17^{\circ}$ is observed which is in good agreement with the DFT results $\left(29.5^{\circ}\right)$ (Tables 1 and S5). All-carbon derivatives of the pqp ligand with the general structure of dibenzo[g,p]chrysene reveal even higher twisting of $29.95-44.95^{\circ} .{ }^{[46,47,49,52]}$

Noteworthy, the pqp ligand reveals stacking with co-crystallized toluene solvent molecule with a distance of 3.267(6) $\AA$. Due to this tilting, atropisomerism can be expected, but in one unit cell only an enantiomeric pair of $\Lambda$ - (chirality at the ruthenium center) with $M$ (chirality at the

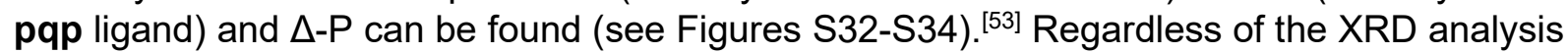
results, atropisomerism which must result from the twisted bridging ligand geometry cannot be excluded as the accompanying diastereomers can remain in solution.

\section{Electrochemistry}

In order to determine the electrochemical properties of Rudpymp, Rupqp and RupqpRh, cyclic voltammetry and differential pulse voltammetry experiments were conducted (see Figures 4 and S4.1-S4.6). All three complexes were studied in acetonitrile solutions (1 $\mathrm{mM})$ containing supporting electrolyte of $\left[\mathrm{Bu}_{4} \mathrm{~N}\right]\left[\mathrm{PF}_{6}\right](0.1 \mathrm{M})$. The data were referenced against the $\mathrm{Fc} / \mathrm{Fc}^{+}$(ferrocene/ferricenium) couple and are summarized in Table 2.

Consistent with literature, the reversible $\mathrm{Ru}(\mathrm{II}) /(\mathrm{III})$ oxidation of both mononuclear complexes appears at $0.81 \mathrm{~V}$ (Rudpymp) and $0.83 \mathrm{~V}$ (Rupqp). The $\mathrm{Ru}(\mathrm{II}) /(\mathrm{III})$ oxidation is insensitive to the peripheral introduction or ring closure of the pyrimidyl moieties. ${ }^{[27]}$ RupqpRh exhibits a reversible $\mathrm{Ru}(\mathrm{II})$-based oxidation at anodically shifted potentials of $0.91 \mathrm{~V}$. The four cathodic events of Rudpymp are reversible or quasi-reversible. Assuming no effect of the new dpymp ligand on the tbbpy ligands, the potentials at $-1.95 \mathrm{~V}$ and $-2.37 \mathrm{~V}$ can be assigned to the latter according to literature results. ${ }^{[27]}$ The one-electron reduction of bare 1,3-pyrimidine takes place at rather negative potentials. ${ }^{[54]}$ Hence, we conclude that the first reductive event of Rudpymp at $-1.67 \mathrm{~V}$ is based on the phenanthroline moiety. This reduction is shifted anodically by circa 100 to $120 \mathrm{mV}$ compared to similar complexes (see Table 2). ${ }^{[27,55]}$ 
Upon ring closure, five reduction events emerge for Rupqp (see also DPV in Figure 4). Thus, the fifth reduction is likely localized on the new bridging ligand architecture. Possibly, it can be either ascribed to the novel central sphere within the pqp ligand or an accessible, second reduction of the pyrimidine units. The redox events at $-1.67 \mathrm{~V}$ (Rudpymp) or $-1.53 \mathrm{~V}$ (Rupqp) without apparent shifts in the oxidation potential of the $\mathrm{Ru}(\mathrm{II}) /(\mathrm{III})$ couple decrease the electrochemical band gap $-\Delta \mathrm{E}($ Rudpymp $)=2.48 \mathrm{eV}$ and $\Delta \mathrm{E}($ Rupqp $)=2.36 \mathrm{eV}-$ compared to $\left[\mathrm{Ru}(\mathrm{tbbpy})_{3}\right]^{2+}(\Delta \mathrm{E}=2.55 \mathrm{eV})$. The coordination of the redox active unit, i.e. $\operatorname{Rh}\left(\mathrm{Cp}^{*}\right)$, induces additional changes.

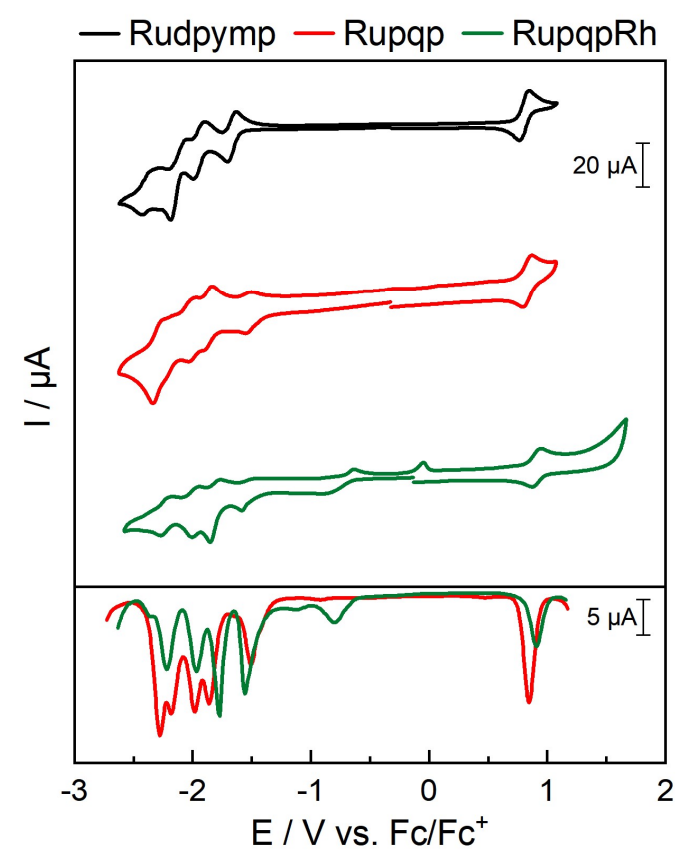

Figure 4. Cyclic voltammograms (top) and differential pulse voltammograms (bottom) of Rudpymp (black), Rupqp (red) and RupqpRh (green) in acetonitrile solution (1 mM) referenced against the ferrocene/ferricenium $\left(\mathrm{Fc} / \mathrm{Fc}^{+}\right)$couple. Conditions: scan rate $0.1 \mathrm{mVs}^{-1}$ (black, green), $0.2 \mathrm{mVs}^{-1}$ (red), $\left[\mathrm{Bu}_{4} \mathrm{~N}\right]\left[\mathrm{PF}_{6}\right]$ at $0.1 \mathrm{M}$ as supporting electrolyte.

First, due to the $\mathrm{Rh}(\mathrm{III})$ metal center, two reduction events at -0.80 and $-1.12 \mathrm{~V}$ appear. They emerge at similar potentials as for the literature-known $\left[R h(b p m)\left(C p^{*}\right) C l\right]^{+}$(with bpm $=4,4^{\prime}-$ bipyrimidine, see Table 2) where a two-fold reduction takes place. In accordance with literature, the rhodium center displays two consecutive reduction steps in case of acetonitrile coordinated species. ${ }^{[56]}$

Second, all subsequent ligand-based reductions emerge at similar potentials as for Rupqp. Only the fifth reduction of Rupqp is shifted considerably in RupqpRh and lies outside of the accessible potential window or it just appears as the small shoulder visible at high cathodic potentials in the CV and DPV (see Figure 4). Interestingly, the $\mathrm{Ru}(\mathrm{II}) /(\mathrm{III})$ oxidation shifts anodically by $80 \mathrm{mV}$. This hints to a more electron deficient $\mathrm{Ru}(\mathrm{II})$ center comparable to $\left[(\mathrm{bpy})_{2} \mathrm{Ru}(\mathrm{bpm})\right]^{2+}\left(\mathrm{E}_{1 / 20 \mathrm{x}}=1.05 \mathrm{~V}\right)$. Alternatively, an increased influence of the $\mathrm{Rh}(\mathrm{III})$ metal center due to the shorter bridging ligand can be considered. For Rutpphz and RutpphzRh $\left(\left[(\text { tbbpy })_{2} \mathrm{Ru}(\mathrm{tpphz}) \mathrm{Rh}\left(\mathrm{Cp}^{*}\right) \mathrm{Cl}\right]^{3+}\right)$ only a $30 \mathrm{mV}$ anodic shift was observed due to coordination of $\operatorname{Rh}\left(\right.$ III). ${ }^{[38]}$

Regardless of the anodically shifted $\mathrm{Ru}$ oxidation, RupqpRh still shows smaller electrochemical bandgap properties of the Rupqp part $(\Delta \mathrm{E}=2.47 \mathrm{eV})$ compared to $\left[(\text { tbbpy })_{3} R u\right]^{2+}$. Since related 5,6-substituted complexes show a comparable effect without any changes in their photophysics, ${ }^{[32,57]}$ steady-state absorption and emission properties of Rudpymp and especially Rupqp and RupqpRh were studied (vide infra). 
Table 2. Electrochemical and spectroscopic properties of Rudpymp, Rupqp and RupqpRh together with suitable substances for comparison. * shoulder

\begin{tabular}{|c|c|c|c|c|c|}
\hline Compound & $\begin{array}{l}\mathrm{E}_{1 / 2 \mathrm{ox}} \\
\mathrm{IV}\end{array}$ & $\begin{array}{l}\mathrm{E}_{1 / 2 \mathrm{red}} \\
/ \mathrm{V}\end{array}$ & $\begin{array}{l}(\text { abs,max }) \lambda_{\text {abs,max }} \\
/ \mathrm{nm}\left(\varepsilon\left[10^{3} \mathrm{M}^{-1} \mathrm{~cm}^{-}\right.\right. \\
\left.{ }_{1}\right]\end{array}$ & $\begin{array}{l}\lambda(\text { em,max }) \\
/ \mathrm{nm}\end{array}$ & $\begin{array}{l}\Phi(e m, \\
A r) / \Phi(e m, \\
\text { air })\end{array}$ \\
\hline$\left[(\text { tbbpy })_{3} R u\right]^{2+[27,57]}$ & 0.73 & $\begin{array}{l}-1.82 \\
-2.02 \\
-2.28\end{array}$ & $451(13)$ & 607 & $9.5 \% / 1.8 \%$ \\
\hline$\left[(\text { tbbpy })_{2} \mathrm{Ru}(\text { phen })\right]^{2+[55]}$ & 0.74 & $\begin{array}{l}-1.77 \\
-1.98 \\
-2.25\end{array}$ & $454(16.0)$ & 610 & - \\
\hline$\left[(\text { tbbpy })_{2} \mathrm{Ru}(\text { phenBr } 2)\right]^{2+[27]}$ & 0.85 & $\begin{array}{l}-1.79 \\
-2.00 \\
-2.32\end{array}$ & $449(14.3)$ & 631 & - \\
\hline Rudpymp & 0.81 & $\begin{array}{l}-1.67 \\
-1.95 \\
-2.18 \\
-2.37\end{array}$ & $\begin{array}{l}451(19.1), 336 \\
(8.16), 285(78.2)\end{array}$ & 631 & $16 \% / 1 \%$ \\
\hline Rupqp & 0.83 & $\begin{array}{l}-1.53 \\
-1.86 \\
-2.01 \\
-2.19 \\
-2.29\end{array}$ & $\begin{array}{l}452(18.8), 336 \\
(17.4), 282(117)\end{array}$ & 637 & $12 \% / 1 \%$ \\
\hline RupqpRh & 0.91 & $\begin{array}{l}-0.80, \\
- \\
1.12{ }^{*} \\
-1.56 \\
-1.77 \\
-1.97 \\
-2.22 \\
-2.36^{*}\end{array}$ & $542,451,336,285$ & 637 & $2 \% / 0 \%$ \\
\hline$\left[\mathrm{Rh}(\mathrm{bpm})\left(\mathrm{Cp}^{*}\right)(\mathrm{Cl})\right]^{+[58]}$ & & -0.92 & 375,364 & - & - \\
\hline
\end{tabular}

\section{Characterization of the Franck-Condon region}

To elucidate the impact of the p-extension of the 1,10-phenanthroline (phen) moiety by a single-bond (Rudpymp) or ring-annulation strategy (Rupqp) on the Franck-Condon region, we employ steady state absorption and resonance Raman (rR) spectroscopy as supported by TDDFT simulations. The discussion starts on the absorption properties of Rudpymp and Rupqp and subsequently turns to the $r R$ data collected upon 405 and $473 \mathrm{~nm}$ excitation. 

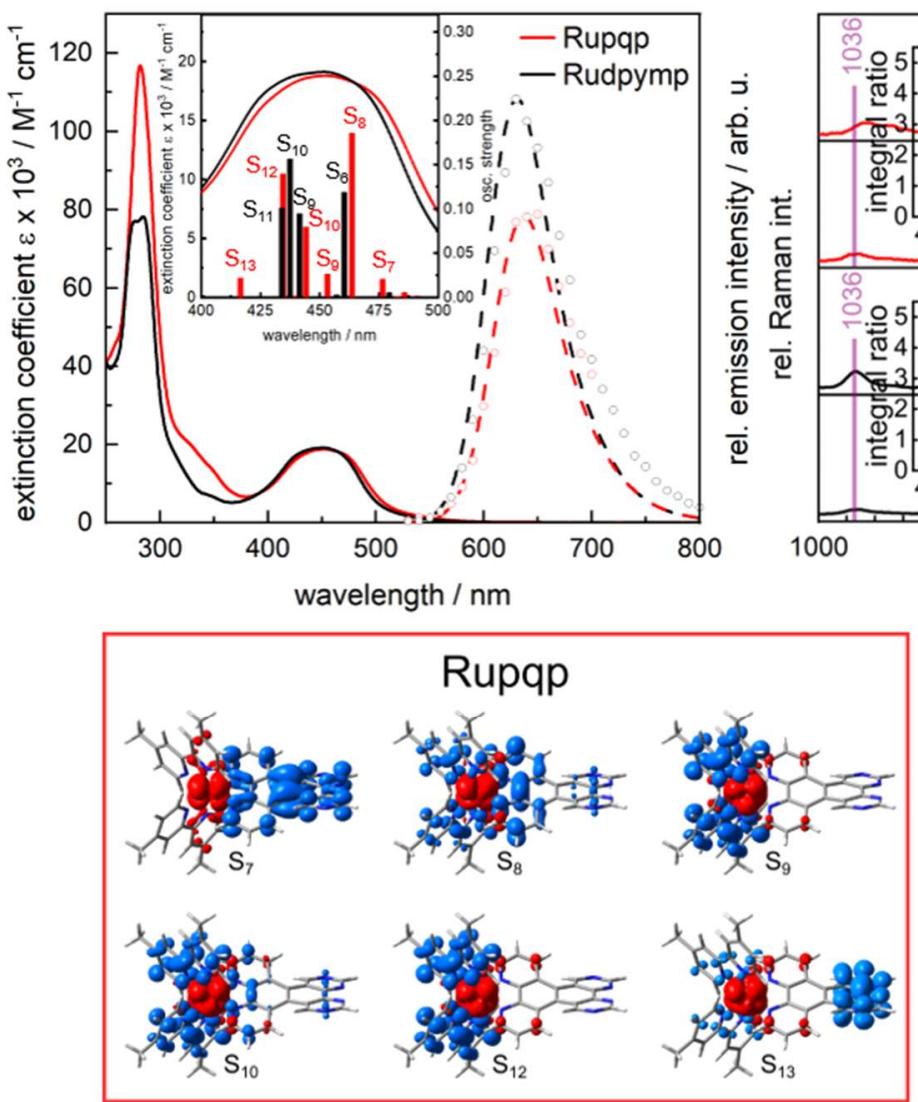
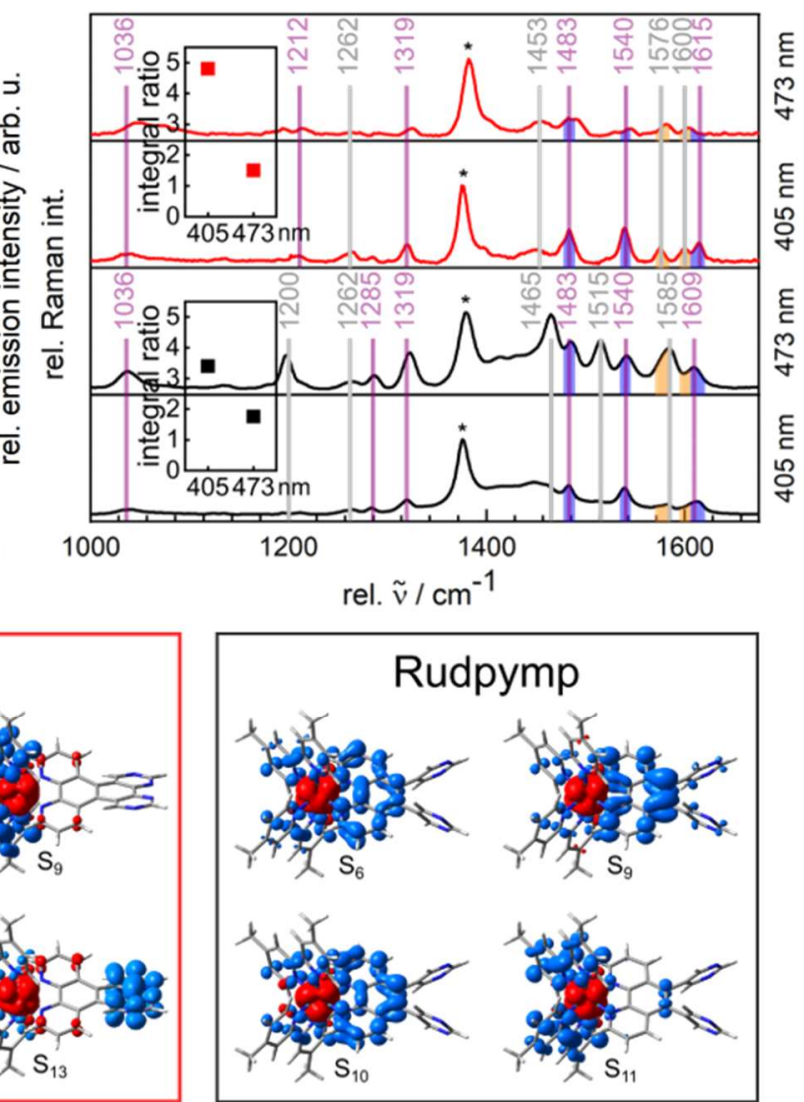

Figure 5. Top left: Extinction coefficients of Rudpymp (black) and Rupqp (red) with relative emissions (dashed) intensities (OD 0.1 at $451 \mathrm{~nm}, \lambda(\mathrm{ex})=451 \mathrm{~nm}$ ), electronic transitions underlying the absorptions bands as obtained at the time-dependent density functional level of theory are indicated in the inlet; top right: resonance Raman spectra of Rudpymp (bottom) and Rupqp (top) upon $405 \mathrm{~nm}$ (bottom) and $473 \mathrm{~nm}$ (top) excitation in acetonitrile. The tbbpy, and dpymp- or pqp-type modes are indicated by violet and grey bars, respectively. The integral ratios of selected modes (tbbpy in light blue relative to dpymp/pqp in light orange) for the respective excitation wavelength are included as insets for Rupqp (red) and Rudpymp (black); integral values are normalized to the integral of the modes of Rudpymp upon excitation with $405 \mathrm{~nm}$, respectively; bottom: charge density differences visualizing main electronic transitions contributing to the electronic absorption of Rudpymp and Rupqp in the visible region; charge transfer takes place from red to blue.

\section{UV/vis absorption.}

The absorption spectrum of the bis-pyrimidyl substituted complex Rudpymp shows three major features: a narrow and strong absorption band at $286 \mathrm{~nm}\left(78.2 \times 10^{3} \mathrm{M}^{-1} \mathrm{~cm}^{-1}\right)$, a weaker shoulder between 300 and $380 \mathrm{~nm}$ and a broad, featureless metal-to-ligand charge-transfer (MLCT) absorption band with a maximum at $451 \mathrm{~nm}\left(19.1 \times 10^{3} \mathrm{M}^{-1} \mathrm{~cm}^{-1}\right)$. Such spectra are typical for [(tbbpy) ${ }_{2} \mathrm{Ru}(\text { phen) }]^{2+}$-type complexes, i.e., where the phen-moiety is substituted in the 5- and 6-position. ${ }^{[27,32]}$ The underlying transitions are composed of bpy-and phen-centered $\pi-\pi^{*}\left(260-380 \mathrm{~nm}\right.$, bpy: $S_{57}$ and $S_{58}$, phen: $\left.S_{66}\right)$ and MLCT transitions $(380-550 \mathrm{~nm}$, MLCT $T_{\text {dpymp: }} S_{6}$ and $S_{9}, M_{\text {LCTy }}: S_{10}$ and $S_{11}$, see Table $S 8.2$ and Figure S8.1).

Although the difference between oxidation and reduction potentials in Rudpymp (2.48 eV, see Table 2) is smaller than in the parent complex $\left[(\text { tbbpy })_{2} R u(\text { phen })\right]^{2+}(2.58 \mathrm{eV})$, the MLCT absorption maxima of both complexes are at around $450 \mathrm{~nm}$. This apparent mismatch between 
the electrochemical data (band gap of $2.48 \mathrm{eV}, 500 \mathrm{~nm}$ ) and the spectroscopic findings indicates the presence of multiple low- energy acceptor orbitals on the dpymp ligand, ${ }^{[60]}$ which participate in the electrochemical process but have vanishing oscillator strengths in the respective MLCT transitions, e.g. $S_{1}$ of MLCT $_{\text {dpymp }}$ character at $2.38 \mathrm{eV}(520 \mathrm{~nm}, \mathrm{f}=0.001)$. Hence, the $\mathrm{MLCT}_{\text {bpy }}$ and $\mathrm{MLCT}_{\text {phen }}$ transitions dominate the absorption spectrum of Rudpymp, explaining the similarity to the absorption data of $\left[(\text { tbbpy })_{2} R u(p h e n)\right]^{2+}$.

Upon ring closure, the molar absorptivity of the MLCT absorption band remains essentially unchanged, while the band at $280 \mathrm{~nm}$ (increase by a factor of 1.5) and the shoulders between 300 and $380 \mathrm{~nm}$ (increase by a factor of 2.1) become more prominent.

TDDFT simulations associate the enhanced absorption band at circa $280 \mathrm{~nm}$ with the increased oscillator strength of the $\pi-\pi^{*}$ excitation of the pqp ligand upon ring $\mathrm{C}-\mathrm{C}$ bond formation (Rupqp: $S_{58}, f=0.514$ versus Rudpymp: $S_{66}, f=0.371$ ). The MLCT band maximum of Rupqp is not shifted with respect to Rudpymp (HOMO-LUMO gap of $2.36 \mathrm{eV}$ ), which is counterintuitive in view of the ring-annulated m-extension of the phen-ligand, i.e., in comparison to Rudape $\left(\left[(\text { bpy })_{2} \mathrm{Ru}(\text { dape })\right]^{2+}\right.$, dape = diazaperylene $),{ }^{[24]}$ Rutape $\left(\left[(\text { bpy })_{2} \mathrm{Ru}(\text { tape })\right]^{2+}\right)^{[14,15,24]}$ or Rueilatin ([(bpy) $\left.)_{2} \mathrm{Ru}(\text { eilatin) }]^{2+}\right)^{[25]}$ where significant bathochromic shifts of the MLCT absorption bands have been observed. ${ }^{[14,15,25]}$ In contrast to these shorter $\pi$-extended ligands, Rupqp reveals a non-planar pqp ligand potentially decreasing m-conjugation. The quantum chemical calculations associate the MLCT band in Rupqp with low-lying $M L_{C} T_{\text {pqp }}$ excitations (into $S_{7}$ and $S_{8}$ ) and higher-lying $M_{L C T}$ bpy (into $S_{10}$ and $S_{12}$ ) excitations. Like for Rudpymp, the lowenergy MLCT excitations have vanishing oscillator strengths (e.g. $S_{1}$, at $2.36 \mathrm{eV}, f=0.001$, see Table S8.4). Consequently, the shape and position of the MLCT absorption band of Rupqp is similar to Rudpymp or the homoleptic reference complex $\left[\mathrm{Ru}(\mathrm{tbbpy})_{3}\right]^{2+}$.

\section{Resonance Raman.}

To further explore the multiple MLCT transitions, rR spectra were collected upon excitation in the red and blue flank of the MLCT absorption band, i.e., at 405 and $473 \mathrm{~nm}$ (see Figure 5) ${ }^{[61]}$. The $r R$ spectra of Rudpymp collected upon 405 and $473 \mathrm{~nm}$ excitation are composed of modes associated to the tbbpy ligands as well as the phen- and pyrimidyl units of the dpymp ligand, respectively. By direct comparison to the homoleptic reference compound $\left[\mathrm{Ru}(\mathrm{tbbpy})_{3}\right]^{2+}$ and the parental complex $\left[(\text { tbbpy })_{2} \mathrm{Ru}(\text { phen })\right]^{2+}$, we assign the modes at 1036 , $1319,1483,1540$ and $1609 \mathrm{~cm}^{-1}$ to the tbbpy ligand sphere. The vibrations centered at 1515 and $1585 \mathrm{~cm}^{-1}$ are assigned to phen-associated modes. ${ }^{[62,63]}$ The $\mathrm{rR}$ modes at 1200, 1262 and $1465 \mathrm{~cm}^{-1}$ are assigned to the pyrimidyl sphere (py), indicating the population of $\mathrm{MLCT}_{\mathrm{py}}$ states. Thus, the rR data supports the initial excitation - as provided by TDDFT - of MLCT bpy $_{\text {as }}$ well as two low-lying MLCT states (MLCT phen and $\mathrm{MLCT}_{\mathrm{py}}$ ) on the dpymp ligand, respectively. The $\mathrm{MLCT}_{\text {phen }}$ gain in relative weight compared to $\mathrm{MLCT}_{\text {tbbpy }}$ states upon shifting the excitation wavelength from 405 to $473 \mathrm{~nm}$, which agrees with the TDDFT results (see Figure 5).

The rR spectra of Rupqp exhibit similar vibrational modes associated with the tbbpy (1036, 1212, 1319, 1483, 1540, $\left.1615 \mathrm{~cm}^{-1}\right)$ and pqp ligand $\left(1262,1543,1576\right.$ and $\left.1600 \mathrm{~cm}^{-1}\right)$. In direct comparison to Rudpymp, the phen-type modes at 1515 and $1585 \mathrm{~cm}^{-1}$ vanish $(473 \mathrm{~nm}$ excitation). However, the integral ratio of the tbbpy-to-dpymp/pqp-type modes (between 1470 and $1620 \mathrm{~cm}^{-1}$ ) is approximately 1.5 for both, Rudpymp and Rupqp at $473 \mathrm{~nm}$ excitation. This indicates similar contributions of the phen acceptor orbital to the Franck-Condon region. Consistent with Rudpymp, the contribution of the pqp ligand to the formation of the initially excited states increases upon shifting the excitation wavelength from 405 to $473 \mathrm{~nm}$. This is reflected in the decrease of the ratio taken between the integral of the tbbpy $(1483,1540$, $1615 \mathrm{~cm}^{-1}$ ) and pqp-type (1576 and $1600 \mathrm{~cm}^{-1}$ ) modes by a factor of circa 2 (see Figure 5). TDDFT supports this trend, revealing low-lying MLCT states with pyrimidyl acceptor orbitals (e.g. $\mathrm{S}_{7}$, see Figure 5). 


\section{Characterization of the long-lived excited states.}

The long-lived excited states are explored by steady-state and time-resolved emission spectroscopy. The emission band maximum of Rudpymp (upon $420 \mathrm{~nm}$ excitation) is located at $631 \mathrm{~nm}$, which is red-shifted with respect to the parental complex [(tbbpy ${ }_{2} R u($ phen $\left.)\right]^{2+}$ $(610 \mathrm{~nm})$ but agrees with $\left.\left[(\text { tbbpy })_{2} \mathrm{Ru}_{\left(p^{2}\right.} \operatorname{phenBr}_{2}\right)\right]^{2+}(631 \mathrm{~nm})$. This indicates that the pyrimidyl substituents influence the $\pi$-system of the phen system. ${ }^{[32]}$

Upon ring-closure (forming Rupqp), the emission maximum is shifted bathochromically by $18 \mathrm{meV}$ to $637 \mathrm{~nm}$. In addition, the comparably high emission quantum yield of $16 \%$ for Rudpymp decreases to $12 \%$ (Rupqp) (see Figure 5, black to red). DFT allows to assign the emissive state in both Rudpymp and Rupqp to a ${ }^{3} \mathrm{MLCT}_{\text {phen }}$ (dpymp: $647 \mathrm{~nm}, 1.92 \mathrm{eV}$, pqp: $657 \mathrm{~nm}, 1.89 \mathrm{eV}$ ), respectively, while the slight bathochromic shift (DFT: $30 \mathrm{meV}$ ) is associated with the increased $\pi$-system upon C-C bond formation (Figure S89).

The respective emission lifetimes of the complexes are $140 \mathrm{~ns}$ (Rudpymp) and $170 \mathrm{~ns}$ (Rupqp, $420 \mathrm{~nm}$ excitation in aerated acetonitrile). Overall, the findings indicate that both, Rudpymp and Rupqp, show emission from a long-lived ${ }^{3} \mathrm{MLCT}$ state, with excess electron density in the proximal ligand sphere, i.e., on the tbbpy ligands and the phen moiety of dpymp and pqp, respectively. The triplet nature of the lowest-lying excited state is corroborated by its sensitivity to oxygen (see Figures S52 and S53). Emission intensities of both complexes decrease significantly upon aeration $(\Phi(\mathrm{em})=1 \%$ for Rudpymp and Rupqp).

\section{Photoinduced dynamics.}

To explore the formation of the long-lived ${ }^{3}$ MLCT state in Rudpymp and Rupqp ultrafast transient absorption (fs-TA) spectra were collected upon $400 \mathrm{~nm}$ excitation The transient absorption spectra of Rudpymp and Rupqp, collected in acetonitrile, reveal a strong groundstate bleach (GSB) between 400 and $500 \mathrm{~nm}$ (the red dashed line reflects the inverted steadystate absorption spectra of the complexes in Figure 6). This GSB is accompanied by strong excited-state absorption (ESA) centered at $350 \mathrm{~nm}$ (Rudpymp) or $340 \mathrm{~nm}$ (Rupqp) as well as broad, spectrally flat ESA at wavelengths longer than $510 \mathrm{~nm}$. The latter features are typically observed for Ru-trisbipyridyl-type complexes and are associated with $\pi-\pi^{*}$ transitions on the reduced tbbpy and phen moieties and ligand-to-metal charge-transfer (LMCT) transitions $(>500 \mathrm{~nm})$.

In Rudpymp, the ESA between 510 and $560 \mathrm{~nm}$ is more pronounced than in Rupqp. The assignment of ESA features can be supported by TD-DFT calculated dipole and spin-allowed transitions of the relaxed triplet states $\left({ }^{3} \mathrm{MLCT}\right)$ : The predictions reveal that the ESA of the long-lived ${ }^{3}$ MLCT excited-states of Rudpymp and Rupqp, mainly stems from $\pi-\pi^{*}$ and LMCT transitions. Moreover, TD-DFT supports the absence of bridge-centered $\pi \pi^{*}$ states which are typically found for structurally related complexes like Rutpphz. ${ }^{[64-66]}$ This hints towards a higher contribution of the phen moiety on the formation of the excited states in Rudpymp compared to Rupqp and agrees with the $\mathrm{rR}$ spectroscopic findings, revealing strong phen-type vibrational modes for Rudpymp, which are absent in the rR spectra of Rupqp.

For both complexes the decay of the sub-ns signals is best described by two characteristic time constants, namely $\mathrm{T}_{1}=2.2 \mathrm{ps}$ and $\mathrm{T}_{2}=134 \mathrm{ps}\left(\right.$ Rudpymp) or $\mathrm{T}_{1}=2.5 \mathrm{ps}$ and $\mathrm{T}_{2}=181 \mathrm{ps}$ (Rupqp), respectively. The corresponding decay associated spectra (DAS) of both, Rudpymp and Rupqp, are qualitatively identical. Hence, we will discuss the excited-state relaxation of both complexes in the framework of the same model. 


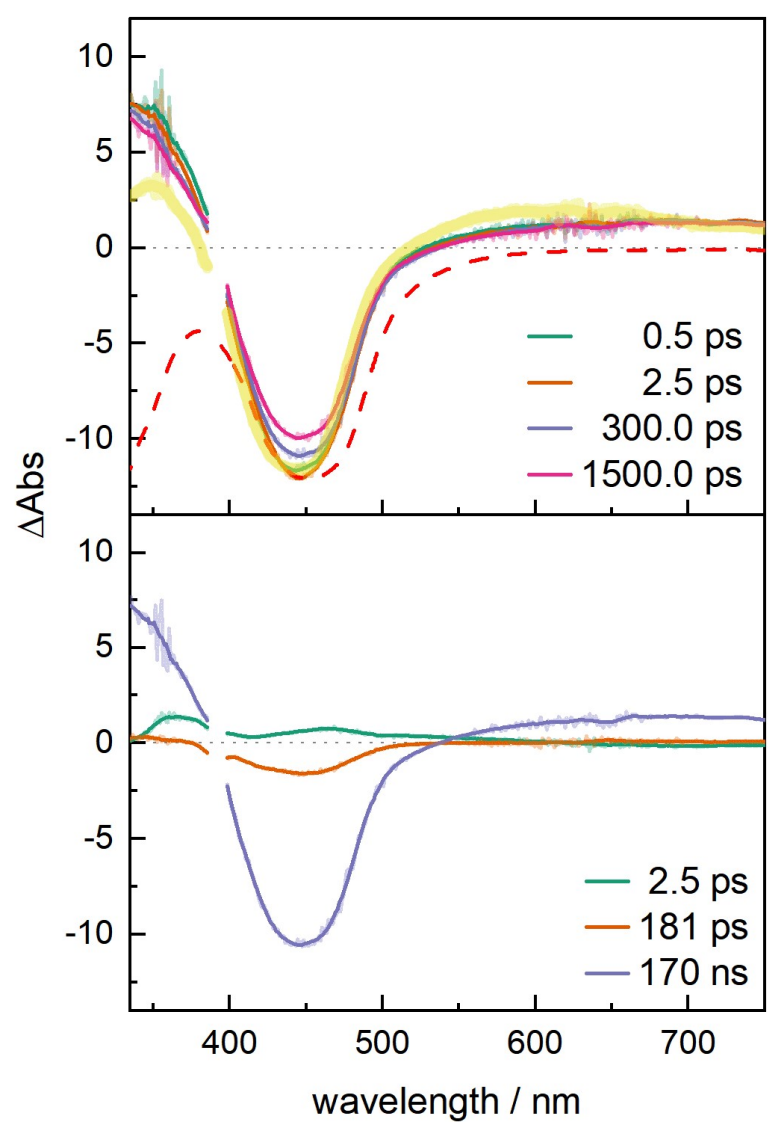

Figure 6. Ultrafast transient absorption (top) and decay-associated spectra (bottom) of Rupqp. The red, dashed line in the upper panel shows the scaled and inverted ground state absorption spectrum. For comparison the transient absorption spectrum of Rudpymp collected at a delay time of $1.5 \mathrm{~ns}$ is shown in yellow. The spectra are collected upon $400 \mathrm{~nm}$ excitation (excitation densities of circa $5 \%$ ) in a delay time range between 0.3 and 2 ns in acetonitrile. The lifetime of the long-lived state is obtained from nanosecond time-resolved emission spectroscopy (see Figure S70 and S71).

The spectral changes associated with $\mathrm{T}_{1}$, as reflected in $\mathrm{DAS}\left(\mathrm{T}_{1}\right)$, are associated with intersystem crossing and vibrational cooling of the initially populated MLCT states. ${ }^{[67-70]}$ This is manifested in the decay of ESA at around $380 \mathrm{~nm}$, associated with $\pi \pi^{*}$ transitions on the reduced tbbpy ligands. This causes a blue-shift of the ESA below $400 \mathrm{~nm}$, accompanied by an increase in the negative signal region. As a result of the processes associated with $\mathrm{T}_{1}, \mathrm{a}$ thermalized ${ }^{3} \mathrm{MLCT}$ with excess electron density localized on the phen moiety is formed. $\mathrm{t}_{2}$ describes the subsequent formation of the long-lived ${ }^{3} \mathrm{MLCT}$ state. This process is associated with at best minute spectral changes in the ESA, however, a partial recovery of GSB features between 400 and $500 \mathrm{~nm}$ is observed.

We associate these findings with a non-radiative decay of a subset of both, ${ }^{3} \mathrm{MC}$ (metalcentered) and ${ }^{3} \mathrm{MLCT}_{\text {py }}$ states as typically observed for $\pi$-extended [(tbbpy) ${ }_{2} R u(\text { phen) }]^{2+}$-type complexes. ${ }^{[71-75]}$ Ultimately, a long-lived excited ${ }^{3} \mathrm{MLCT}$ state, with excess electron density on the tbbpy ligands (Rupqp) or both, the phen and tbbpy moieties (Rudpymp) is populated by the process associated with $\mathrm{T}_{2}$. These increased contributions of the phen moiety on long-lived excited state agrees with the blue-shift of the emission maximum of Rudpymp compared to Rupqp. 
pqp as bridging ligand - formation of dinuclear complexes and explorative light-driven redox catalysis.

After ensuring the $\left[\mathrm{Ru}(\mathrm{bpy})_{3}\right]^{2+}$-like excited-state dynamics of Rudpymp and Rupqp, the effect of coordinating a second metal center at the new coordination sphere of Rupqp was examined. Upon coordination of the $\left[\mathrm{Rh}(\mathrm{III})\left(\mathrm{Cp}^{*}\right)(\mathrm{X})\right]$ moiety to the bridging ligand complex Rupqp a shoulder at $520 \mathrm{~nm}$ emerges in the absorption spectrum which is in line with quantum chemical calculations (Figure S85). Molecular orbitals available for $\mathrm{MLCT}_{\mathrm{pqp}}$ transitions at long wavelengths ( $\mathrm{S}_{6}$ in Table S11) from $\mathrm{Ru}(\mathrm{II})$ to the pq-sphere of the pqp ligand are energetically stabilized $(2.26 \mathrm{eV}$ ) compared to Rupqp (2.55 eV). Possibly due to high contributions of the bis-pyrimidyl moiety, the excited state subsequently deactivates radiationless by electron transfer to the appended $\mathrm{Rh}(\mathrm{III})$ center. Compared to the ring-closed Rupqp coordination of $\mathrm{Rh}$ leads to further attenuation of the emission quantum yield from $12 \%$ (Rupqp) to $2 \%$ (RupqpRh) (see Figure 7, red to green).

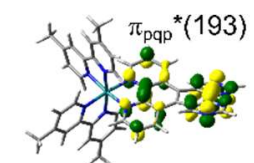

$\mathrm{MLCT}_{\mathrm{pqp}}\left(\mathrm{S}_{4}\right)$

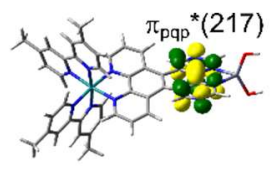

$\mathrm{MLCT}_{\mathrm{pqp}}\left(\mathrm{S}_{29}\right)$

$2.55 \mathrm{eV}(486 \mathrm{~nm}), 0.006 \quad 2.57 \mathrm{eV}(483 \mathrm{~nm}), 0.056$

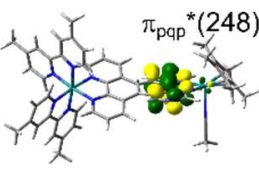

$\operatorname{MLCT}_{\text {pqp }}\left(\mathrm{S}_{4}\right)$

$2.26 \mathrm{eV}(549 \mathrm{~nm}), 0.017$

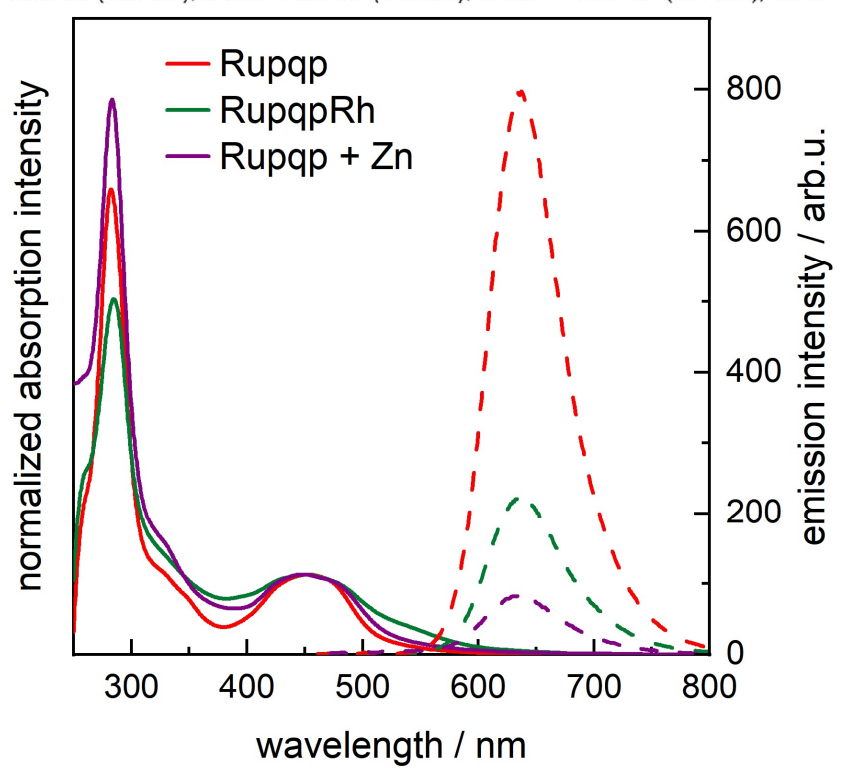

Figure 7. Top: excitation energies, wavelengths and oscillator strengths of low-lying $M C_{\text {pqp }}$ excitations and involved $\pi_{\text {pqp }}{ }^{*}$ for Rupqp $\left(S_{4}\right)$, RupqpZn $\left(S_{29}\right)$ and RupqpRh $\left(S_{4}\right)$; bottom: absorption and emission spectra of Rupqp, RupqpRh and Rupqp + [Zn(BF $\left.)_{2}\right]$; absorption spectra were normalized at $451 \mathrm{~nm}$; emission spectra were recorded upon excitation at $451 \mathrm{~nm}$ (OD 0.1).

Similarly, addition of redox-inactive $\mathrm{Zn}\left(\mathrm{BF}_{4}\right)_{2}$ to Rupqp induces emission quenching (see Figure 7) as has been observed for Rutpphz complexes. ${ }^{[76,77]}$ Opposite to Rh(III), Zinc(II) induces inverse changes in the frontier molecular orbitals of ground and excited states associated with the pqp ligand (see Figures 7 and S83 and S88; MO in Figure 7 is located at slightly higher energies than for Rupqp), i.e. with the spindensity of the lowest triplet state centered on the Ru(III) and the adjacent phen-sphere. Possibly, the predominant excited state localization on the phen part of the pqp ligand enhances charge recombination and thus effective quenching of the ${ }^{3} \mathrm{MLCT}$ emission occurs. From both $\mathrm{Rh}(\mathrm{III})$ and $\mathrm{Zn}$ (II) coordination it becomes clear that the order of the frontier molecular orbitals of Rupqp can be altered depending on the respective second metal center. Thus, the pqp appears to be split into two halves with either phen and/or pyrimidyl contributions. Compared to the situation with Rupqp, 
addition of $\mathrm{Zn}(\mathrm{II})$ to Rudpymp does not alter absorption or emission behaviour (see Figure S55 and S56). Consequently, the ring closure is required for the interaction with a second metal center.

Finally, the dinuclear complex RupqpRh was investigated for the possibility of redox catalysis. Due to the silver contamination found by AAS, all catalytic experiments were accompanied by exclusion experiments with addition of $\mathrm{AgPF}_{6}$.

First, the principal ability of the RhCp* fragment to run formate-driven, chemical catalysis by reduction of the nicotinamide co-factor $\mathrm{NAD}^{+}$was investigated (see mechanism reported in literature $\left.{ }^{[78,79]}\right)$. To further exclude an effect of the mononuclear complex on the reduction to $\mathrm{NADH}$, Rupqp was investigated as well. A water/acetonitrile $(4: 1, v: v)$ solution of formate $(50 \mathrm{mM})$ and the respective complex $(5 \mu \mathrm{M})$ was mixed with 40 eq. of $\mathrm{NAD}^{+}$. Upon thermal activation (room temperature, $40^{\circ} \mathrm{C}, 50^{\circ} \mathrm{C}$ ), only RupqpRh shows conversion of $\mathrm{NAD}^{+}$to $\mathrm{NADH}$ (visible by the increasing absorbance at $340 \mathrm{~nm}$ with $\varepsilon \varepsilon(\mathrm{NADH})=6300 \mathrm{M}^{-1} \mathrm{~cm}^{-1[80]}$ and an increasing emission intensity at about $460 \mathrm{~nm}$ ). As depicted in Figure 8, with increasing temperature, the catalysis is significantly faster. Interestingly, the thermal redox catalysis reaches a plateau already at about $50 \%$ conversion.

As the rhodium center offers the possibility to run redox catalysis, the dinuclear complex was subjected to conditions where the catalytically competent $\mathrm{Rh}(\mathrm{I})$ intermediate can be formed photochemically (excitation with $470 \mathrm{~nm}, 50 \mathrm{mWcm}^{-2}$ ). As it can be seen in Figure 593 , the two-fold reduced $\mathbf{R u}(\mathrm{II})$ pqpRh(I) dyad can be built up upon illumination $(470 \mathrm{~nm}, 40-$ $50 \mathrm{mWcm}^{-2}$ ). The band is bathochromically shifted by about $50 \mathrm{~nm}$ compared to $\left[(\text { tbbpy })_{2} \mathrm{Ru}(\mathrm{tpphz}) \mathrm{Rh}\left(\mathrm{Cp}^{*}\right)\right]^{2+}$ due to the more electron withdrawing nature of the pqp ligand. ${ }^{[38]}$ As light-induced reduction was successful with RupqpRh, electron transfer from Ru towards Rh can be expected.

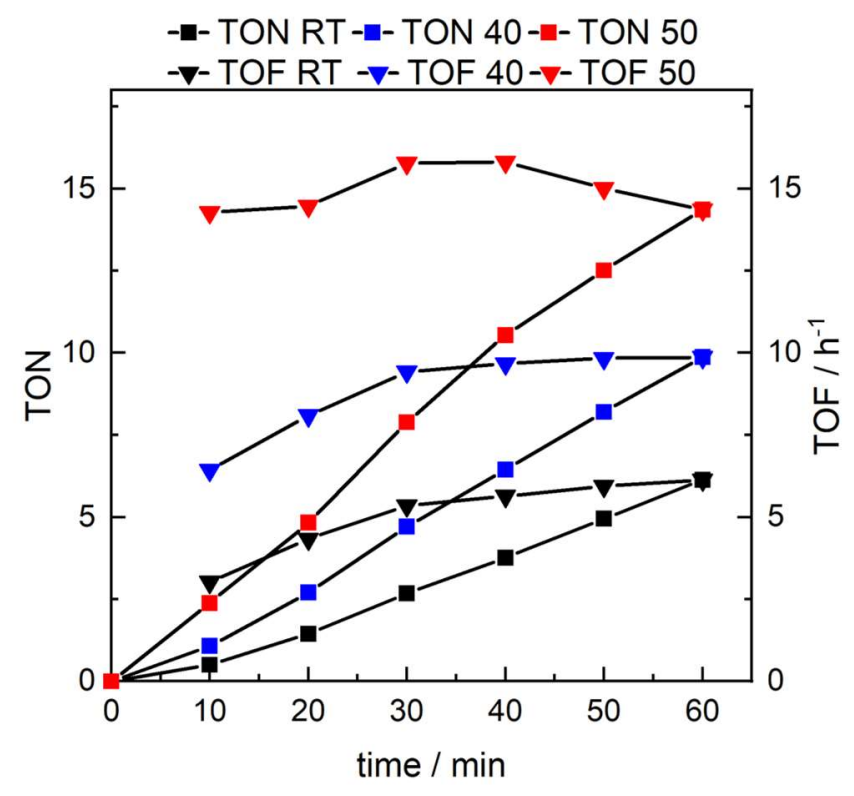

Figure 8. Light-induced redox catalysis of RupqpRh at room temperature (black), $40^{\circ} \mathrm{C}$ (blue) and $50^{\circ} \mathrm{C}$ (red) in water/acetonitrile mixtures $(4: 1, v: v)$; concentrations used RupqpRh $(5 \mu \mathrm{M})$, $\mathrm{NAD}^{+}(200 \mu \mathrm{M})$, TEA $(0.12 \mathrm{M})$ and $\mathrm{NaH}_{2} \mathrm{PO}_{4}(0.1 \mathrm{M})$, excitation with $470 \mathrm{~nm}\left(50 \mathrm{mWcm}^{-2}\right)$. 
Lastly, we examined if the light-driven $\mathrm{Rh}(\mathrm{III}) /(\mathrm{I})$ conversion can be accompanied with the reduction of nicotinamide co-factor $\mathrm{NAD}^{+}$. In phosphate-buffered solution containing triethylamine as electron donor, the dyad RupqpRh was irradiated with blue light. Conversion of $\mathrm{NAD}^{+}$to $\mathrm{NADH}$ was again checked by absorption and emission spectroscopy. RupqpRh again was the only catalytically active compound tested in this series of experiments. All other exclusion experiments revealed either radical-mediated product formation of $\mathrm{NAD}_{2}{ }^{[81]}$ by Rupqp or Rupqp with addition of silver hexafluorophosphate or no conversion for $\left[\mathrm{Ru}(\mathrm{tbbpy})_{3}\right]^{2+}$ (see ESI, Figure S98). With elevated temperatures, the conversion with RupqpRh is progressively enhanced. An increase in turnover number from 5 (RT) to $10\left(40^{\circ} \mathrm{C}\right)$ and $15\left(50^{\circ} \mathrm{C}\right)$ can be observed.

\section{Experimental Section.}

For detailed information see the Supporting Information: experimental and synthetic details, structural characterization via NMR, mass spectrometry, single-crystal X-ray diffraction, reaction screening, electrochemical characterization, emission lifetimes, steady-state and transient spectroscopy, qualitative element analysis by TXRF and GFAAS and quantum chemical simulations.

Deposition numbers CCDC 2111036 (for Rudpymp) and 2111037 (for Rupqp) contain the supplementary crystallographic data for this paper. These data are provided free of charge by the joint Cambridge Crystallographic Data Centre and Fachinformationszentrum Karlsruhe via www.ccdc.cam.ac.uk/structures.

\section{Conclusion}

Pyrimidoquinxoalinophenanthroline, pqp, has been synthesized and proven to function as a new bridging ligand fostering light-driven catalysis. This novel bridging ligand was accessed via a dehydrogenative chemistry on the Ru-complex approach fusing two pyrimidine spheres via a geminate C-C-bond. The respective pyrimidine units were introduced to a $\mathrm{Ru}$ (II) 5,6dibromo-1,10-phenanthroline moiety using Suzuki or Stille cross coupling beforehand. From a structural point of view, the resultant Ru polypyridine complex Rupqp fills the gap of previously reported tape- and tpphz-based systems as it exhibits two central aromatic rings rather than one or three, respectively. Due to the twisted nature of the novel bridging ligand that has been revealed by scXRD as well as DFT methods, the steady-state as well as the excited-state properties resemble those of prototype $\left[R u(b p y)_{3}\right]^{2+}$. This is explained by theoretical investigations and detailed, time-resolved photophysical studies, suggesting a subdivision of the pqp bridging ligand into two weakly coupled subunits. However, the energetics of the orbitals on the pqp ligand can be significantly influenced by coordination of a second metal center. The coordination of both, $\mathrm{Zn}$ (II) and $\mathrm{Rh}(\mathrm{III})$, lead to a quenching of the luminescence due to a redistribution of the frontier molecular orbitals as revealed by quantum chemistry. Furthermore, the introduction of $\mathrm{Rh}(\mathrm{III})\left(\mathrm{Cp}^{*}\right)$ leading to RupqpRh renders access to visible light-driven photocatalytic reduction of naturally occurring nicotinamide $\mathrm{NAD}^{+}$to $\mathrm{NADH}$. These promising results point towards a coordination-induced switching of excited-state localization of Rupqp. As the nature of the coordinated metal determines the location of excited states to a large degree, further exploitation towards tuneable photocatalysis will be possible. 


\section{Acknowledgements}

J.B., C.M., A.K.M., S.G., S.K., B.D. and S.R. gratefully acknowledge the funding by the Deutsche Forschungsgemeinschaft (DFG, German Research Foundation) - Projektnummer 364549901 - TRR 234 [A1 and C5]. J.B. is thankful for financial support by the Fonds der Chemischen Industrie $(F C l)$ for a Kekulé-Stipendium. T.M. thanks the Deutscher Akademischer Austauschdienst (DAAD, German Academic Exchange Service) for a study scholarship for graduates (91733810). The authors gratefully acknowledge Andrea Hainthaler (Friedrich-Schiller University Jena) for the time-resolved emission measurements, Ilse Friedländer for $\mathrm{rR}$ measurements (Friedrich-Schiller University Jena) and Dominik Blaimer (Ulm University) for GFAAS measurements of Ag.

\section{References}

[1] W. W. Fischer, J. Hemp, J. E. Johnson, Annu. Rev. Earth Planet. Sci. 2016, 44, 647683.

[2] D. F. Harrison, E. Weissberger, H. Taube, Science (80-. ). 1967, 159, 320-322.

[3] C. Creutz, H. Taube, J. Am. Chem. Soc. 1969, 91, 3988-3989.

[4] C. Creutz, H. Taube, J. Am. Chem. Soc. 1973, 95, 1086-1094.

[5] G. M. Tom, C. Creutz, H. Taube, J. Am. Chem. Soc. 1974, 96, 7827-7829.

[6] V. Balzani, G. Bergamini, F. Marchioni, P. Ceroni, Coord. Chem. Rev. 2006, 250, 1254-1266.

[7] L. De Cola, F. Barigelletti, V. Balzani, P. Belser, A. von Zelewsky, C. Seel, M. Frank, F. Vögtle, Coord. Chem. Rev. 1991, 111, 255-260.

[8] H. Ozawa, M. A. Haga, K. Sakai, J. Am. Chem. Soc. 2006, 128, 6-10.

[9] S. Rau, B. Schäfer, D. Gleich, E. Anders, M. Rudolph, M. Friedrich, H. Görls, W. Henry, J. G. Vos, Angew. Chemie - Int. Ed. 2006, 45, 6215-6218.

[10] G. F. Manbeck, K. J. Brewer, Coord. Chem. Rev. 2013, 257, 1660-1675.

[11] M. Schulz, M. Karnahl, M. Schwalbe, J. G. Vos, Coord. Chem. Rev. 2012, 256, $1682-$ 1705.

[12] G. Li, D. Zhu, X. Wang, Z. Su, M. R. Bryce, Chem. Soc. Rev. 2020, 49, 765-838.

[13] S. Serroni, S. Campagna, F. Puntoriero, C. Di Pietro, N. D. Mc Clenaghan, F. Loiseau, Chem. Soc. Rev. 2001, 30, 367-375.

[14] T. Brietzke, W. Mickler, A. Kelling, U. Schilde, H. J. Krüger, H. J. Holdt, Eur. J. Inorg. Chem. 2012, 4632-4643.

[15] T. Brietzke, W. Mickler, A. Kelling, H. J. Holdt, Dalt. Trans. 2012, 41, 2788-2797.

[16] M. G. Pfeffer, T. Kowacs, M. Wächtler, J. Guthmuller, B. Dietzek, J. G. Vos, S. Rau, Angew. Chemie - Int. Ed. 2015, 6627-6631.

[17] M. G. Pfeffer, B. Schäfer, G. Smolentsev, J. Uhlig, E. Nazarenko, J. Guthmuller, C. Kuhnt, M. Wächtler, B. Dietzek, V. Sundström, S. Rau, Angew. Chemie - Int. Ed. 2015, 54, 5044-5048.

[18] S. Ernst, V. Kasack, W. Kaim, Inorg. Chem. 1988, 27, 1146-1148.

[19] R. A. Pavinato, J. A. Walk, M. E. McGuire, Inorg. Chem. 1993, 32, 4982-4984. 
[20] D. P. Rillema, K. B. Mack, Inorg. Chem. 1982, 21, 3849-3854.

[21] M. Hunziker, A. Ludi, J. Am. Chem. Soc. 1977, 99, 7370-7371.

[22] K. R. Brereton, C. L. Pitman, T. R. Cundari, A. J. M. Miller, Inorg. Chem. 2016, 55, 12042-12051.

[23] A. Chouai, S. E. Wicke, C. Turro, J. Bacsa, K. R. Dunbar, D. Wang, R. P. Thummel, Inorg. Chem. 2005, 44, 5996-6003.

[24] E. C. Glazer, Y. Tor, Angew. Chemie 2002, 114, 4194-4198.

[25] D. Gut, A. Rudi, J. Kopilov, I. Goldberg, M. Kol, J. Am. Chem. Soc. 2002, 124, 54495456.

[26] J. Bolger, A. Gourdon, E. Ishow, J.-P. Launay, Inorg. Chem. 1996, 35, 2937-2944.

[27] A. Stumper, T. D. Pilz, M. Schaub, H. Görls, D. Sorsche, K. Peuntinger, D. Guldi, S. Rau, Eur. J. Inorg. Chem. 2017, 2017, 3799-3810.

[28] F. Doettinger, Y. Yang, M. A. Schmid, W. Frey, M. Karnahl, S. Tschierlei, Inorg. Chem. 2021, 60, 5391-5401.

[29] K. L. Billingsley, K. W. Anderson, S. L. Buchwald, Angew. Chemie 2006, 118, 35643568.

[30] N. Kudo, M. Perseghini, G. C. Fu, Angew. Chemie - Int. Ed. 2006, 45, 1282-1284.

[31] L. C. Campeau, K. Fagnou, Chem. Soc. Rev. 2007, 36, 1058-1068.

[32] J. Brückmann, A. A. Heidecker, D. Popovic, A. K. Mengele, D. Nauroozi, P. Bäuerle, S. Rau, Eur. J. Inorg. Chem. 2019, 2019, 1832-1838.

[33] S. Monro, C. G. Cameron, X. Zhu, K. L. Colón, H. Yin, T. Sainuddin, M. Hetu, M. Pinto, A. Fuller, L. Bennett, J. Roque, W. Sun, S. A. McFarland, Photochem. Photobiol. 2019, 95, 267-279.

[34] J. Sherwood, J. H. Clark, I. J. S. Fairlamb, J. M. Slattery, Green Chem. 2019, 21 , 2164-2213.

[35] L. Jedinák, R. Zátopková, H. Zemánková, A. Šustková, P. Cankař, J. Org. Chem. 2017, 82, 157-169.

[36] V. Farina, S. Kapadia, B. Krishnan, C. Wang, L. S. Liebeskind, J. Org. Chem. 1994, 59, 5905-5911.

[37] L. S. Liebeskind, R. W. Fengl, J. Org. Chem. 1990, 55, 5359-5364.

[38] A. K. Mengele, S. Kaufhold, C. Streb, S. Rau, Dalt. Trans. 2016, 45, 6612-6618.

[39] U. Kölle, M. Grützel, Angew. Chem. Int. Ed. 1987, 26, 567-570.

[40] C. White, A. Yates, P. M. Maitlis, Inorg. Synth. 1992, 29, 228-234.

[41] S. Kaufhold, L. Petermann, D. Sorsche, S. Rau, Chem. - A Eur. J. 2017, 23, $2271-$ 2274.

[42] P. V. R. Schleyer, H. Jiao, Pure Appl. Chem. 1996, 68, 209-218.

[43] J. A. N. F. Gomes, R. B. Mallion, Chem. Rev. 2001, 101, 1349-1383.

[44] M. G. Pfeffer, C. Pehlken, R. Staehle, D. Sorsche, C. Streb, S. Rau, Dalt. Trans. 2014, 43, 13307-13315.

[45] S. D. Bergman, D. Reshef, S. Groysman, I. Goldberg, M. Kol, Chem. Commun. 2002, 


\section{2, 2374-2375.}

[46] H. juan Yu, J. ping Liu, Z. feng Hao, J. He, M. Sun, S. Hu, L. Yu, H. Chao, Dye. Pigment. 2017, 136, 416-426.

[47] X. S. Ke, Y. Hong, V. M. Lynch, D. Kim, J. L. Sessler, J. Am. Chem. Soc. 2018, 140, 7579-7586.

[48] R. C. Fortenberry, C. M. Novak, T. J. Lee, P. P. Bera, J. E. Rice, ACS Omega 2018, 3, 16035-16039.

[49] T. Hatakeyama, S. Hashimoto, S. Seki, M. Nakamura, J. Am. Chem. Soc. 2011, 133, 18614-18617.

[50] F. H. Herbstein, Acta Crystallogr. Sect. B Struct. Crystallogr. Cryst. Chem. 1979, 35, 1661-1670.

[51] N. Yoshida, S. Kamiguchi, K. Sakao, R. Akasaka, Y. Fujii, T. Maruyama, T. Iwasawa, Tetrahedron Lett. 2020, 61, 152033.

[52] Y. Ueda, H. Tsuji, H. Tanaka, E. Nakamura, Chem. - An Asian J. 2014, 9, 1623-1628.

[53] L. Ademi, E. C. Constable, C. E. Housecroft, M. Neuburger, S. Schaffner, Dalt. Trans. 2003, 3565-4567.

[54] J. E. O'Reilly, P. J. Elving, J. Am. Chem. Soc. 1971, 93, 1871-1879.

[55] B. Schäfer, H. Görls, S. Meyer, W. Henry, J. G. Vos, S. Rau, Eur. J. Inorg. Chem. 2007, 4056-4063.

[56] J. A. Hopkins, D. Lionetti, V. W. Day, J. D. Blakemore, Organometallics 2019, 38, 1300-1310.

[57] P. Wintergerst, A. K. Mengele, D. Nauroozi, S. Tschierlei, S. Rau, Eur. J. Inorg. Chem. 2019, 2019, 1988-1992.

[58] K. Suzuki, A. Kobayashi, S. Kaneko, K. Takehira, T. Yoshihara, H. Ishida, Y. Shiina, S. Oishi, S. Tobita, Phys. Chem. Chem. Phys. 2009, 11, 9850-9860.

[59] M. Ladwig, W. Kaim, J. Organomet. Chem. 1991, 419, 233-243.

[60] S. Campagna, F. Puntoriero, F. Nastasi, G. Bergamini, V. Balzani, Top. Curr. Chem. 2007, 280, 117-214.

[61] M. Wächtler, J. Guthmuller, L. González, B. Dietzek, Coord. Chem. Rev. 2012, 256, 1479-1508.

[62] C. V. Kumar, J. K. Barton, I. R. Gould, N. J. Turro, J. Van Houten, Inorg. Chem. 1988, $27,648-651$.

[63] M. Karnahl, S. Krieck, H. Görls, S. Tschierlei, M. Schmitt, J. Popp, D. Chartrand, G. S. Hanan, R. Groarke, J. G. Vos, S. Rau, Eur. J. Inorg. Chem. 2009, 2009, 4962-4971.

[64] L. Zedler, J. Guthmuller, R. de M. Inês, S. Kupfer, S. Krieck, M. Schmitt, J. Popp, S. Rau, B. Dietzek, I. Rabelo de Moraes, S. Kupfer, S. Krieck, M. Schmitt, J. Popp, S. Rau, B. Dietzek, Chem. Commun. 2014, 50, 5227-5229.

[65] L. Zedler, A. K. Mengele, K. M. Ziems, Y. Zhang, M. Wächtler, S. Gräfe, T. Pascher, S. Rau, S. Kupfer, B. Dietzek, Angew. Chemie - Int. Ed. 2019, 58, 13140-13148.

[66] M. Martynow, S. Kupfer, S. Rau, J. Guthmuller, Phys. Chem. Chem. Phys. 2019, 21, 9052-9060.

[67] C. W. Stark, W. J. Schreier, J. Lucon, E. Edwards, T. Douglas, B. Kohler, J. Phys. 
Chem. A 2015, 119, 4813-4824.

[68] S. Wallin, J. Davidsson, J. Modin, L. Hammarström, J. Phys. Chem. A 2005, 109, 4697-4704.

[69] N. H. Damrauer, G. Cerullo, A. Yeh, T. R. Boussie, C. V. Shank, J. K. McCusker, Chemtracts 1998, 11, 621-625.

[70] R. A. Malone, D. F. Kelley, J. Chem. Phys. 1991, 95, 8970-8976.

[71] J. Olofsson, B. Önfelt, P. Lincoln, J. Phys. Chem. A 2004, 108, 4391-4398.

[72] M. Kaufmann, C. Müller, A. A. Cullen, M. P. Brandon, B. Dietzek, M. T. Pryce, Inorg. Chem. 2021, 60, 760-773.

[73] C. Müller, D. Isakov, S. Rau, B. Dietzek, J. Phys. Chem. A 2021, 125, 5911-5921.

[74] G. E. Shillito, C. B. Larsen, J. R. W. McLay, N. T. Lucas, K. C. Gordon, Inorg. Chem. 2016, 55, 11170-11184.

[75] J. Schindler, Y. Zhang, P. Traber, J. F. Lefebvre, S. Kupfer, M. Demeunynck, S. Gräfe, M. Chavarot-Kerlidou, B. Dietzek, J. Phys. Chem. C 2018, 122, 83-95.

[76] Y. Liu, A. Chouai, N. N. Degtyareva, D. A. Lutterman, K. R. Dunbar, J. Am. Chem. Soc. 2005, 127, 10796-10797.

[77] S. A. Tysoe, R. Kopelman, D. Schelzig, Inorg. Chem. 1999, 38, 5196-5197.

[78] H. C. Lo, C. Leiva, O. Buriez, J. B. Kerr, M. M. Olmstead, R. H. Fish, Inorg. Chem. 2001, 40, 6705-6716.

[79] C. L. Pitman, O. N. L. Finster, A. J. M. Miller, Chem. Commun. 2016, 52, 9105-9108.

[80] K. T. Oppelt, E. Wo, M. Stiftinger, W. Scho, W. Buchberger, Inorg. Chem. 2013, 52, 11910-11922.

[81] T. Golaś, E. Bojarska, B. Czochralska, J. Photochem. Photobiol. A Chem. 1990, 54, 333-347. 